\title{
Cécile Reynaud, Liszt et le virtuose romantique
}

\section{Lise Sabourin}

\section{(2) OpenEdition}

\section{Journals}

\section{Édition électronique}

URL : http://journals.openedition.org/studifrancesi/9607

DOI : 10.4000/studifrancesi.9607

ISSN : 2427-5856

\section{Éditeur}

Rosenberg \& Sellier

\section{Édition imprimée}

Date de publication : 1 décembre 2007

Pagination : 683

ISSN : 0039-2944

\section{Référence électronique}

Lise Sabourin, « Cécile Reynaud, Liszt et le virtuose romantique », Studi Francesi [En ligne], 153 (LI | III) | 2007, mis en ligne le 30 novembre 2015, consulté le 12 janvier 2021. URL : http://

journals.openedition.org/studifrancesi/9607 ; DOI : https://doi.org/10.4000/studifrancesi.9607

\section{Ce document a été généré automatiquement le 12 janvier 2021.}

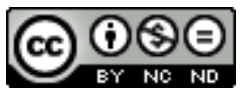

Studi Francesi è distribuita con Licenza Creative Commons Attribuzione - Non commerciale - Non opere derivate 4.0 Internazionale. 


\title{
Cécile Reynaud, Liszt et le virtuose romantique
}

\author{
Lise Sabourin
}

\section{RÉFÉRENCE}

CÉCILE REYNAUD, Liszt et le virtuose romantique, Paris, Honoré Champion, 2006, pp. 403.

1 Cécile Reynaud, musicologue conservateur à la Bibliothèque nationale de France, nous invite à cerner le statut spécifique du virtuose romantique, en s'appuyant sur le corpus de la «Revue musicale» de Fétis, le père de la «musicologie comparée» (p. 25), et les écrits de Liszt. L'époque romantique voit naître une considération nouvelle de l'interprète dans la mesure où il se révèle aussi créateur et, au-delà, des rapports de la musique et de la littérature dans une société qui oscille entre divertissement et idéal esthétique.

2 La philosophie allemande donnait à la musique instrumentale une profondeur d'essence que ne percevait pas nécessairement - même s'il sut écouter Beethoven - le public, ni même la critique contemporaine, qui préférait s'attacher au verbe des romances à la française ou aux opéras de Rossini. Mais la virtuosité des musiciens romantiques sur l'instrument nouveau qu'est le piano-forte, a fortiori l'excellence de Liszt, inventeur visionnaire de formes, capable en outre de théoriser après Hoffmann, changent cette perception. Libérée des mots, même si le poids des Lieder reste important, la musique proclame son «autonomisation» artistique, tout en s'inscrivant en parallèle de la littérature.

3 L'évolution des institutions (classes de l'Institut, musées...) aide à cette mutation des mentalités: du Beau idéal, mimétique de la nature, on en vient, à la suite de Ballanche et Chateaubriand, à apprécier davantage encore la réalisation de son imaginaire par l'artiste, autre mage, autre prophète. Outre sa parenté avec le poète, l'interprète trouve sa place auprès du compositeur, l'instrument soliste rivalise avec l'orchestre: Liszt met 
en partition pour piano la Symphonie fantastique de Berlioz, le virtuose «aspire au renouvellement de la musique par son alliance avec la poésie» (p. 27).

4 L'ouvrage s'organise en trois temps après une bonne introduction (pp. 11-30). D'abord C. Reynaud met en place les conditions d'épanouissement de la musique instrumentale en cet âge d'or romantique (pp. 31-138): théorique et pratique, attitude des critiques face aux virtuoses, mutation des pianos. Puis (pp. 139-248), partant du corpus de la «Revue musicale», mais aussi de la Biographie universelle des musiciens et de La Musique mise à la portée de tout le monde de Fétis (1830), elle montre comment les virtuoses (Karlbrenner, Moscheles, Herz, Thalberg) ont subi leurs procès, avant que Liszt ne conquière définitivement les cœurs par sa pratique de génie, mais aussi par sa fonction d'analyse de Berlioz et Chopin, sa réflexion sur le rôle du musicien dans la société objet de la troisième partie (pp. 249-336), avant une riche bibliographie (pp. 363-396) et L'index nominum (pp. 397-398).

5 La virtuosité, «pensée» et «invention» comme le dira Valéry, a mené Liszt à la composition, qu'il confort dans une perspective morale et sociale, même s'il reste plus prudent que les poètes du temps sur son influence réelle. Il est cependant à l'avantgarde de la révolution wagnérienne qui saura l'apprécier autant que Baudelaire avait aimé dès 1863 l'auteur de Tannhaüser: la musique s'est réapproprié les moyens de la poésie. 